\title{
ESPERA, MORTE E INCERTEZA: A INSTALAÇÃO DOS JULGAdOS NAS MINAS DE GOIÁS - LEITURAS SOBRE A CRIAÇÃO DE VILA BOA
}

Fernando Lobo Lemes

ernandolobolemes@gmail.com

Resumo: A partir dos embriões de aparelhos administrativos que definiam os contornos do governo colonial, a instalação dos Julgados, passo inicial em direção a um ordenamento institucional mais sólido, aparece como estratégia provisória de organização das ações coordenadas por Lisboa nas minas de Goiás. Neste contexto, a partir da observação de modificações políticas criadas por uma situação de espera, propomos uma leitura possível sobre a criação de Vila Boa, ao analisar a emergência de eventos de natureza intermediária, marcados pela incerteza, a exemplo da morte do governador da Capitania de São Paulo. Eventos que revelam reações e adaptações entre protagonistas, cujos interesses produzem composições e recomposições, formatando o cenário político e institucional das minas de Goiás.

Palavras-Chave: Goiás; Julgados; Espera; Governo Colonial.

\section{As minas de Goiás antes de VILA Boa: fRAGILIDAde dos meCANISMOS administrativos E DO PODER POLÍTICO DA COROA}

Até 1739, ano de criação de Vila Boa, os interesses da Coroa portuguesa, manifestos através da implantação inicial de uma rede de instituições políticas e administrativas, estavam representados muito timidamente em Goiás. Com exceção da presença do ouvidor e superintendente-geral, cargo com status de ministro, apenas alguns "embriões de aparelho administrativo" (SOUZA, 2001, p. 14) definiam os contornos institucionais da monarquia portuguesa nas minas de Goiás: uma superintendência-geral, baseada numa pequena malha de cargos e funções e uma força militar ainda pouco imponente compunham todo o aparato do governo colonial.

Embora a ausência de vilas e de órgãos governamentais enraizados solidamente revelasse certa fragilidade do poder real, movimentos de rebeldia

* Doutorado na Université Sorbonne Nouvelle - Paris 3. 
dos potentados locais, buscando confirmar suas próprias autonomias, tinham provocado uma contrapartida da Coroa, permitindo ao rei de Portugal impor suas vontades nos espaços políticos francamente abertos das minas de Goiás. No entanto, as estruturas governativas implantadas à época eram ainda insuficientes para garantir um mínimo de controle desejado. Neste aspecto, importa-nos, aqui, sublinhar a relação entre as instituições administrativas e o alcance do poder da Coroa. Admitindo-se a administração como um núcleo autônomo (HESPANHA, 1989, p. 37) através do qual se exerce de fato o poder político do rei, é impossível negar que a capacidade de constrangimento e de controle das populações locais por parte dos oficiais da Coroa permanecesse visivelmente limitada.

A ação política efetiva do monarca distante dependia diretamente dos meios humanos disponíveis e da disseminação de estruturas institucionais, o que apenas com o tempo poderia ser implementado. Assim, em função da ausência de um poder institucional orquestrado localmente, ou devido a sua incipiência e fragilidade, as relações de poder em Goiás assumem um caráter de independência, onde os próprios funcionários e ministros do rei se vêm convertidos num pólo político autônomo, com um considerável poder de decisão, notadamente quanto aos assuntos ligados a seus interesses particulares. ${ }^{1}$ Tal assertiva está plenamente de acordo com certos estudos sobre a historia do poder que consideram a burocracia ligada à Coroa, da mesma forma que os oficiais de nomeação régia, como um pólo político no seio dos sistemas de poderes do Império (HESPANHA, 1989, p. 416).

Esta presença apenas parcial das instituições da monarquia nos primeiros tempos das minas de Goiás contribuiu largamente para a criação de formas de organização políticas espontâneas e autônomas, de difícil regulação por parte da Coroa, onde a trama dos interesses tendia a incrementar iniciativas de caráter particulares. A coexistência destas formas de organização e sua reprodução acabam por se repetir e se atualizar, produzindo resultados práticos e institucionais. Noutras palavras, a ausência efetiva dos mecanismos administrativos da Coroa autorizava a institucionalização de formas alternativas de organização política, fundamentadas, principalmente, nos princípios de autonomia dos núcleos de poder locais.

Entretanto, esta condição inicial não se prolongaria por muito tempo. Em que pese ter sido breve sua passagem pelas minas de Goiás, a presença do governador da Capitania de São Paulo, Antônio Luís de Távora, o Conde de Sarzedas, a partir de 1737, iria alterar esta configuração inicial, reposicionando estrategicamente os projetos e as intenções de Lisboa nos quadros das relações de poder nas minas de Goiás. 
2. A obra incompleta do governador de São Paulo: Presença e morte de Antônio LUIS dE TÁvORA NAS MINAS DE GOIÁS

Enviado às minas de ouro pelo monarca português, Luís de Távora levava consigo a missão de escolher o melhor sítio para estabelecer a primeira vila na região dos índios goiases. Contudo, uma série de outros problemas o aguardavam. Logo após sua chegada, promoveu uma grande reunião no arraial de Meia Ponte e, constituindo uma Junta de "ministros", no dia 4 de fevereiro de 1737, desencadeia um conjunto de iniciativas que podem ser resumidas, basicamente, em três direções distintas: em primeiro lugar, buscando impor uma solução definitiva quanto às questões levantadas pela instituição do novo método da Capitação ${ }^{2}$, deliberou sobre os valores que seriam pagos por escravo e pelo comércio local, primeiro passo para conquistar a adesão dos mineiros das minas de Carlos Marinho, recentemente rebelados e atraídos pelo governo da Capitania do Grão-Pará e Maranhão. Em segundo lugar, tratou de ampliar os mecanismos diretos de arrecadação dos direitos reais, como confirma o intendente e provedor da Fazenda Real, Sebastião Mendes de Carvalho, presente na Junta de Meia Ponte. Segundo ele, o Conde de Sarzedas, considerando as grandes distâncias entre os diversos povoados, "ordenou que fora desta principal intendência de Sant 'Anna [centro político e administrativo colonial], houvesse em cada arraial uma comissária" (AHU, GO, Cx. 1, D. 50). Assim, a antiga intendência das minas de Goiás, dividida posteriormente em duas, a de Sant 'Anna e a de Tocantins (PALACIN, 2001, p. 39), se desdobravam agora em diversas comissárias, instituídas pelo governador e criadas através da atuação do intendente Mendes de Carvalho. Além disso, o governador Antônio Luís de Távora determinou, ao mesmo intendente e provedor, o início imediato das matrículas (inscrições) dos escravos existentes em toda a extensão das minas, base de cálculo para a cobrança da Capitação referente ao primeiro semestre de 1737 (AHU, GO, Cx. 1, D. 50).

Em terceiro lugar, visando o controle mais efetivo das populações mineradoras e consciente de que a criação de uma única vila, como havia determinado o monarca, seria insuficiente para promover a estabilidade necessária e o conseqüente equilíbrio político nas minas de Goiás, o Conde de Sarzedas optou pela adoção e antecipação de outra metodologia: a convocação de eleições nos arraiais para a indicação de juízes ordinários, responsáveis pelo funcionamento das instâncias jurídicas e administrativas locais.

Cerca de um ano depois, em carta de 17 de maio de 1738, o novo superintendente-geral das minas, Agostinho Pacheco Teles, escrevia ao

Fernando Lobo Lemes. Espera, mORTE E INCERTEZA: a InSTALAÇÃo dos JulGados nas minas de Golás... 
monarca dando conta de que "se assentou uma junta de Ministros que se achava naquela parte convocados pelo governador de São Paulo, o Conde de Sarzedas [...]", na qual se definiu que,

enquanto Vossa Majestade se não servia mandar criar Vilas nas povoações a que chamam arraiais, se elegessem na forma da lei dois juízes ordinários em cada um deles e um Tabelião do público judicial e notas, e um meirinho para servirem com os ditos juízes (AHU, GO, Cx. 1, D. 60).

Na mesma carta, Pacheco Teles informava ao rei de Portugal que as ordens recebidas do governador a este respeito foram cumpridas, tendo sido "atendida a necessidade que padeciam os povos daquelas Minas de administração de justiça pela distância em que ficam umas povoações das outras" (AHU, GO, Cx. 1, D. 60).

Após a realização da Junta, enquanto o intendente e provedor, Sebastião Mendes de Carvalho, se dirigia aos arraiais de Meia Ponte e Crixás, o governador Antônio Luís de Távora seguia em direção ao Tocantins, região norte de Goiás, a fim de dar início, ele próprio, ao processo de inscrição dos escravos nas minas de Carlos Marinho.

Por sua vez, depois de cumprir a missão determinada pela Junta, o intendente Mendes de Carvalho, escrevendo ao monarca em maio de 1737, nos dá pistas a respeito do itinerário seguido pelo Conde de Sarzedas:

o [superintendente-geral das minas] doutor Gregório Dias, e o dito Conde General passou a Tocantins e com o Dr. Agostinho Pacheco a fazer ali a matrícula e para reduzir a obediência a este governo Carlos Marinho, que totalmente almejava, persuadindo que estava protegido, e sujeito ao Governo do Maranhão: só por fraudarem indevidamente os direitos a Vossa Majestade e interessarem-se em propinas e utilidades (AHU, GO, Cx. 1, D. 50).

Ainda na mesma carta, escrita do arraial de Sant 'Anna, o intendente avisava ao rei de Portugal, que havia sido informado "que o Conde ainda está no Tocantins; e o Dr. Agostinho Pacheco passara a Carlos Marinho, associado de Dragões vindos das [Minas] Gerais" (AHU, GO, Cx. 1, D. 50).

Alguns meses depois, no dia 19 de novembro, o mesmo Mendes de Carvalho, confirmava o sucesso das medidas empreendidas por Sarzedas no Tocantins. Segundo ele, havia sido "reduzido em obediência a este governo o arraial de Carlos Marinho", conhecido, desde então, como arraial "conquistado" (AHU, GO, Cx. 1, D. 53). 
O governador, certamente após longa jornada de negociações, realizou a matrícula dos escravos e fez nomeações dos novos responsáveis pela arrecadação dos direitos reais para as intendências das minas de Carlos Marinho e do Tocantins.

Contudo, no caminho de volta ao arraial de Sant 'Anna, Antônio Luís de Távora adoece e morre em Traíras. Sua obra nas minas de Goiás restaria incompleta. Não obstante, teve tempo para deixar importantes instruções ao novo superintendente-geral, Agostinho Pacheco Teles, cujas ações, a partir de então, imprimiriam novo fôlego aos projetos de Lisboa, estabelecendo marcada continuidade com as estratégicas iniciadas pelo governador da Capitania de São Paulo.

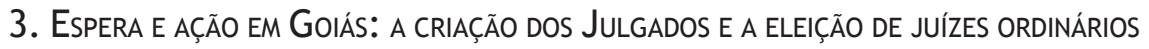

Agostinho Pacheco Teles havia sido nomeado em substituição a Gregório Dias da Silva, por carta régia de 11 de fevereiro de 1736 (AHU, GO, Cx. 1, D. 24). Coincidentemente, no mesmo dia em que o rei João V havia ordenado ao Conde de Sarzedas que se dirigisse aos sertões da América com o objetivo de instalar a primeira vila na região mineradora de Goiás (AHU, GO, Cx. 1, D. 25).

No entanto, se a morte do governador parecia colocar os planos do monarca num compasso de espera, ${ }^{3}$ a presença do superintendente-geral, revestido de um poder que a ausência do governador lhe conferia, indicava a execução de um projeto que, se não coincidia exatamente com as expectativas anunciadas anteriormente, demonstrava que o tempo de espera a que estavam submetidos súditos e monarca, não criava a sensação de um vazio institucional. Ao contrário, traria consigo uma nova dinâmica nas relações de força e poder nas minas de Goiás.

Se a criação de uma vila, determinação exclusiva do rei e competência específica dos governadores, estava adiada indefinidamente, os procedimentos adotados pelo superintendente-geral, seguindo os passos definidos pela Junta de Meia Ponte, iriam compensar de forma relativa aquela impossibilidade.

Assim, naquele mundo dos arraiais, onde o poder e as vontades do rei de Portugal permaneciam limitados, tomava forma um primeiro esboço de ordenamento político no conjunto urbano de Goiás. Escrevendo de Sant'Anna de Goiás, em 17 de maio de 1738, Agostinho Pacheco Teles justificava as ações que capitaneava, pois tinha consciência de que a criação de instituições políticas em terras de além-mar ultrapassavam os limites de suas atribuições. Diz ele que,

Fernando Lobo Lemes. Espera, morte e incerteza: a instalaçÃo dos Julgados nas minas de Goiás... 
Não se ignora que esta criação de juízes e oficiais [...] é só própria da regalia de Vossa Majestade, mas a precisa necessidade de manter os povos em justiça e sossego [...], a arrecadação da Real Fazenda, juntamente com a notória dificuldade de recurso a Vossa Majestade, fez parecer conveniente a seu Real Serviço este procedimento provisional, dependente da sua real aprovação, interpretada pela urgência dos incidentes a que se não podia de outra maneira dar o remédio pronto que estavam pedindo (AHU, GO, Cx. 1, D. 60).

Apesar de compreendido como procedimento provisório, como afirma o próprio superintendente-geral, este mecanismo, inaugurado ainda em 1737, assumiu os contornos de uma forma de governo, instalada antes da criação da primeira vila (Vila Boa de Goiás foi criada em 1739), funcionando ao longo de todo o século XVIII como instrumento e locus da ação política nas minas de Goiás. Conhecidos como Julgados, ${ }^{4}$ tal forma de organização jurídica e administrativa, baseada na eleição de membros das elites locais, foi o primeiro passo em direção a um ordenamento institucional mais sólido, fundamentando estrategicamente o avanço das intenções políticas de Lisboa.

Na condição de superintendente-geral das minas de Goiás, Pacheco Teles justifica a promoção de eleições para a escolha de juízes ordinários - alegando, sobretudo, a instabilidade dos arraiais, devido à intensa mobilidade dos habitantes das minas - com o objetivo de ampliar seu comando e sua liderança, tanto com relação à manutenção da ordem local, quanto ao controle dos cofres reais (Real Fazenda), trazendo para si, em consonância com o desenho da estrutura governativa do Império português, o domínio das decisões da justiça em segunda instância.

Demonstrando notável capacidade de articulação, durante este tempo intermediário entre a morte do governador de São Paulo e a nomeação e chegada de seu sucessor, Agostinho Pacheco Teles transita com bastante habilidade desde as instâncias de poder locais até as distantes esferas de decisões em Lisboa. Neste sentido, escreve ao rei de Portugal revelando suas convicções:

Sendo Vossa Majestade servida aprovar esta forma de administração de justiça e eleição de juízes ordinários com apelação e agravo para esta superintendência, ficará desnecessário o estabelecimento de Vilas em cada arraial por agora [...], já que [...] nenhum deles promete permanência, pela facilidade com que seus habitantes se transportam para qualquer outro descobrimento em largas distancias (AHU, GO, Cx. 1, D. 60). 
Mostrando-se extremamente útil neste momento atravessado por grandes incertezas quanto ao futuro, a estratégia levada a cabo pelo superintendente-geral parece ter encontrado a aprovação da Coroa: antecipando a eleição de juízes ordinários, o monarca ganhava tempo e, no compasso e ritmo impostos pelas condições do momento, podia definir com mais clareza o caminho através do qual deveriam avançar os projetos de Lisboa nas minas de Goiás.

\section{A incerteza dos acontecimentos: leituras sobre a criação de Vila Boa de Goiás}

Esta especificidade de Goiás, definida pela incerteza diante de acontecimentos inesperados, como a morte do governador e o adiamento do ato de criação da primeira vila, conduzindo a decisões marcadas pela urgência (a exemplo da eleição de juízes ordinários antes da instituição do senado da câmara - instituição cuja existência e função são associadas às vilas em todo o Império português), produziu um ambiente de difícil interpretação por parte dos historiadores. Não é sem razão que Moraes (2005) propõe uma leitura inusitada a respeito da criação e instalação da primeira vila nas minas de Goiás. Segundo a autora, com a vinda do sucessor do Conde de Sarzedas, o novo governador de São Paulo, Luiz de Assis Mascarenhas, em 1739, a vila teria sido "erigida" de fato, através da demarcação dos lugares destinados aos logradouros públicos, já que teria sido criada anteriormente pela Provisão Régia de fevereiro de 1736.

Discordando das narrativas escritas, que afirmam que a vila teria sido criada ou instalada apenas em 1739, e fundamentando-se em documentos encontrados no Arquivo Histórico Ultramarino de Lisboa, bem como em fragmentos de uma Ata de Vereança, datada de 1738, disponível no Arquivo Frei Simão Dorvi, na Cidade de Goiás, Pereira Moraes alega que teria havido eleições para a composição de um concelho municipal, antes da instalação de Vila Boa, em 1739. Após a transcrição dos documentos citados, a autora expõe de forma conclusiva sua análise:

Esses dois documentos comprovam que o Capitão General de São Paulo, Dom Luiz de Mascarenhas, veio não somente demarcar os logradouros, mas efetivar o que de fato já estava acontecendo, a Vila fora criada em 1736 e erigida em 1739 , quer dizer, fundar a vila era criar sua administração através da Câmara Municipal e, erigi-la, dentre outras providências, eram os atos de demarcar o logradouro e de mandar erguer os prédios públicos (MORAES, 2005, p. 50-51). 
A hipótese proposta na obra em apreço parece guardar certa coerência quando se considera, como afirmamos anteriormente, o ambiente opaco que caracteriza o período, sem a clarividência objetiva que poderíamos encontrar noutras situações, bem demarcadas por acontecimentos ordenados cronologicamente dentro de um padrão comum que se repete na maioria dos casos de fundação de vilas no Império.

Contudo, algumas considerações devem ser feitas. Inicialmente, a exposição que se segue foi pensada apenas com o escopo de introduzir o debate, provocando, se porventura for o caso, uma correção de rumos nas leituras e interpretações a respeito dos acontecimentos associados à criação de Vila Boa de Goiás. Secundariamente, do nosso ponto de vista, a simples referência ao tema teria o mérito de contribuir para a compreensão mais detalhada do processo de fundação da primeira vila em Goiás.

Assim, em primeiro lugar, ainda que se possa constatar a realização de eleições para a escolha de juízes ordinários em alguns arraiais, entendemos que é preciso pensar melhor a respeito da hipótese sobre a existência de uma câmara municipal no arraial de Sant 'Anna, antes da criação ou instalação oficial da primeira vila (Vila Boa de Goiás), por iniciativa do governador Luiz de Assis Mascarenhas.

Em segundo lugar, é importante refletir a respeito dos efeitos da ordem do monarca para a criação de uma vila nas minas de Goiás, materializada através da Provisão Real de 1736, já que ela, por si só, não institui automaticamente o funcionamento de uma câmara municipal, devendo ser seguido todo um ritual que envolve a instituição de um senado da câmara, sob a autoridade e presença do governador da Capitania. Tal procedimento não foi adotado pelo Conde de Sarzedas, quando esteve em Goiás durante o primeiro semestre de 1737, o que proporcionou o surgimento de um cenário muito particular em Goiás: um tempo intermediário se instala entre a urgência na condução dos projetos coloniais e a implantação prática de mecanismos institucionais de controle político e administrativo, capazes de imprimir novos códigos de poder no jogo político das minas.

Neste caso, acreditamos que não devemos nos contentar apenas com a evidência das seqüências ou etapas marcadas pelo passo a passo oficial dos cerimoniais que caracterizam a imposição paulatina do poder real, através da fundação de uma vila. No caso específico das minas de Goiás é indispensável buscar compreender o que se passou neste espaço intermediário, neste momento de transição, entre o desejo e a ordem manifesta do rei de Portugal para a criação de uma vila e sua materialização no plano concreto dos acontecimentos. 
Na verdade, estes tempos intermediários, recorrentes em determinados momentos da história, reivindica do historiador certas precauções. Desde logo, como nos lembra Vidal (2005a, p. 254), os intervalos ou "tempos de espera" não devem ser vistos, necessariamente, como momentos ou "tempos" de "imobilidade", pois, muito pelo contrário, podem constituir verdadeiros "momentos de precipitação". Da mesma forma, e por isso mesmo, a morte do Conde de Sarzedas, governador da Capitania de São Paulo, não produziu um vazio institucional, nem mesmo uma paralisia nas ações regidas pela Coroa. Ao contrário, uma nova dinâmica, baseada na criação de Julgados e na eleição de membros das elites locais para o governo dos arraiais, nos convida a uma leitura que aponta para outras possibilidades, permitindo ver a escolha de outras estratégias, redefinindo as interpretações a respeito dos caminhos e das estratégias que conduziram à criação da primeira vila nas minas de Goiás.

\section{Elementos para o debate: a autoria da CRiação de Vila Boa, a preeminência do} arraial de Sant'Anna e as eleições tardias em Meia Ponte e Crixás

Após a decisão do monarca, em fevereiro de 1736, ordenando que Antônio Luís de Távora fundasse uma vila em Goiás, há um lapso de tempo até sua partida efetiva, já que o governador viaja de São Paulo em direção às minas apenas no final do ano, pressionado pelos acontecimentos em Goiás e em obediência a outra ordem da Coroa, verdadeira intimação do rei de Portugal. Contudo, ao chegar às minas de ouro, o Conde de Sarzedas não cria imediatamente a vila, um dos objetivos de sua presença em Goiás, pois dá prioridade à solução de outros problemas (notadamente às questões ligadas aos valores a serem adotados para a regularização do recolhimento da Capitação nos núcleos mineradores próximos ao rio Tocantins e aos litígios que envolviam a definição das fronteiras entre as Capitanias do norte da América portuguesa). Provavelmente, preparava o terreno para que, num ambiente de maior tranqüilidade e harmonia com os grupos locais, promovesse o ritual da criação da primeira vila nas minas de Goiás.

Contudo, sabendo que estava autorizado a criar uma única vila e consciente da larga dimensão geográfica das minas, cujas distâncias demandavam uma estrutura de governo muito mais ampla, optou pela criação dos Julgados, estabelecendo distritos regionais nos núcleos mineradores em que não se cogitava a fundação de vilas. Para este desiderato havia encarregado o superintendente-geral Agostinho Pacheco Teles. Contudo, por obra do destino, o Conde de Sarzedas faleceu antes de concluir efetivamente seu 
projeto. Assim, do ponto de vista dos agentes da Coroa, privados da existência e funcionamento de uma vila e das instituições coloniais que lhes emprestariam um controle mais efetivo sobre o campo político das minas de Goiás, se instala um tempo de espera, marcado por uma espécie de ruptura momentânea com o projeto idealizado anteriormente.

Neste contexto, não deve haver dúvidas de que Antônio Luís de Távora não criou realmente a vila, pois não teve o tempo que esperava. E isso nos confirma seu próprio sucessor, Luiz de Assis Mascarenhas, em requerimento dirigido ao rei de Portugal, no qual reivindica uma remuneração pelos serviços prestados para a criação de Vila Boa de Goiás. Alegando ter executado "em tudo as ordens dirigidas ao Conde de Sarzedas para a criação de uma Vila nos Goiás", Assis Mascarenhas afirma ser ele mesmo o fundador da vila que seu antecessor não pôde fundar ou estabelecer (A HU, GO, Cx. 7, D. 549).

De fato, em 1752, ao solicitar ao rei José I uma ajuda de custo pela viagem realizada às minas de Goiás, Assis Mascarenhas argumenta que os herdeiros do Conde de Sarzedas foram recompensados

por ordem do Senhor Rei D. João, [...] pai de Vossa Majestade, em atenção a ter ido as mesmas minas para levantar outra Vila, ação que não se viu efetiva, porque impensadamente lhe roubou a morte tão estimável gloria e mandou o mesmo Senhor se entregassem doze mil cruzados aos seus herdeiros (AHU, GO, Cx. 7, D. 549).

Mesmo assim, por outro lado, se Vila Boa de Goiás e o senado da câmara não foram instituídos por iniciativa do governador Antônio Luís de Távora, este fato não desautoriza a afirmação de que tenha havido eleições em alguns núcleos mineradores, para a escolha de juízes ordinários, responsáveis pela justiça em primeira instância e pela administração dos arraiais. Portanto, a existência de atas de vereanças, que descrevem as reuniões periódicas realizadas pelos eleitos e suas decisões a respeito dos problemas urbanos, apenas confirma que a determinação do governador para a eleição de juízes ordinários foi cumprida à risca pelo superintendente-geral Pacheco Teles.

Assim, ainda no primeiro semestre de 1737, pondo em prática os planos do governador morto, Pacheco Telles procedia à eleição dos juízes ordinários em três localidades diferentes: nas minas de São Félix, nas povoações das chamadas Terras Novas e nas minas do Tocantins. Vale notar que não houve simplesmente nomeações diretas, mas um processo eleitoral baseado na legislação vigente, ${ }^{5}$ que provê os cargos pelo período de três anos. O próprio superintendente-geral afirma que, depois de realizadas as eleições, levou com ele 
as pautas (listas com nomes dos eleitos) para por elas nos dois anos seguintes tirar as pessoas que deverão servir de juízes ordinários naquelas povoações por não haver arca (cofre) de Concelho em que se guardassem os pelouros, e findo que foi o ano de $1737 \mathrm{em}$ que acabaram de servir os juízes para ele eleitos pelas ditas pautas tirei outras para o presente ano de 1738, mandando-se expedir cartas de Confimação tomado juramento entraram por elas a servir (AHU, GO, Cx. 3, D. 225).

Outro importante pormenor deve ser considerado: a escolha das localidades para a realização das eleições dos juízes ordinários não foi aleatória. Pacheco Teles seguia uma tendência perceptível na leitura dos documentos da época. Neste aspecto, como o objetivo do Conde de Sarzedas era criar a primeira vila nas proximidades de um dos arraiais mineradores, um passo importante teria sido a escolha do lugar ideal para sua fundação. Esta escolha Sarzedas também não fez, posto que faleceu antes, deixando em aberto a definição do sítio no qual ela seria instalada. ${ }^{6}$

Surpreendido pela morte repentina de Luís de Távora e aguardando as providências que tomaria seu sucessor, o superintendente-geral não deu prosseguimento ao processo eleitoral em três arraiais que, pessoalmente, julgava possuir as condições adequadas para a instalação da primeira vila. É ele mesmo quem, em carta escrita no ano seguinte, em 1738, explica ao monarca sua decisão:

Como se faleceu o dito Governador em Tocantins em 29 de agosto do ano passado em tempo que ia para aquela povoação [e como eu] havia voltado das Minas de São Félix, me não resolvi, passando para Meia Ponte a fazer ali a eleição dos tais juízes, nem em Sta. Anna e Crichás. Assim porque [...] lhe podia dar melhor providência como por esperar a determinação do Novo Governador Gomes Freire de Andrade (AHU, GO, Cx. 3, D. 225).

Assim, por sua própria conta e risco, Agostinho Pacheco Teles selecionava os lugares para a eleição de Julgados, reservando os arraiais de Meia Ponte, Sant'Anna e Crixás como indicação de prováveis sítios ideais para a instalação da primeira ou das primeiras vilas nas minas de Goiás. Mas a pausa imposta pelo desaparecimento de Sarzedas foi interrompida tão logo Gomes Freire de Andrade, governador do Rio de Janeiro, assumiu interinamente o governo da Capitania de São Paulo. Por sua vez, o novo governador determinou ao superintendente-geral das minas, por carta de 18 de fevereiro de 1738, que realizasse eleições também nos arraiais de Sant'Anna, Meia Ponte e Crixás. Nas palavras de Pacheco Telles, 
Este [Gomes Freire de Andrade] me avisa por carta de 18 de fevereiro, recebida em 27 de abril próximo, proceda à dita eleição de juízes também nos referidos arraiais da Meia Ponte, Santanna e Crichás e dê conta a Vossa Majestade; Assim o farei quando sair deste arraial de Santanna, onde presentemente me assisto e passar ao de Crichás (AHU, GO, Cx. 3, D. 225).

Entretanto, apesar da resolução de Freire de Andrade, o superintendente-geral acata apenas parcialmente sua orientação. Mais tarde, noutra carta dirigida ao rei de Portugal em outubro de 1739, Pacheco Teles esclarece os procedimentos que havia adotado quanto às eleições nos outros três arraiais. Segundo ele,

ao Governador e Capitão General Gomes Freire de Andrada, quando sucedeu neste governo, lhe pareceu conveniente esta providência e me avisou a continuasse, em carta sua de fevereiro do dito ano [...] e procedendo a eleição de juízes ordinários nas Minas de Crichás, como havia feito nos outros Arraiais, ficaram somente sem eles este de Sta. Anna, e o de Meia Ponte, por se esperar novo governador para criar a Villa em hum deles; chegou o atual D. Luis Mascarenhas, e como se resolveu a criá-la na vizinhança deste arraial de Sta. Anna [...] com o titulo de Va. Boa, me recomendou fizesse eleição de juízes ordinários no Arraial da Meia Ponte, como fiz antes de fazer a dos juízes ordinários, vereadores e procurador para a Vila (AHU, GO, Cx. 3, D. 225).

Como vemos, parece claro o fato de não ter havido eleições para juízes ordinários em Sant 'Anna, nos mesmos moldes dos outros arraiais. Nem, tampouco, a primeira vila teria sido criada nas minas de Goiás antes da chegada, em 1739, do governador Luiz de Assis Mascarenhas, tendo sido reservados pelo superintendente-geral como prováveis sítios para sua instalação os arraiais de Sant' Anna e o de Meia Ponte. Em setembro de 1739, outra carta do mesmo Pacheco Teles, desta vez dirigida aos juízes ordinários eleitos nas minas do Tocantins, confirma a estratégia seguida pela Coroa quanto à criação dos Julgados nas minas de Goiás e a realização tardia de eleições nos arraiais de Sant 'Anna e Meia Ponte. Em meio a uma discussão sobre a autonomia e o poder das autoridades eleitas nos arraiais antes da criação de Vila Boa, Pacheco Teles lembra que

aos mesmos juízes ordinários pertence toda a jurisdição, e administração dos rendimentos públicos e do bom Regime desta terra, pois tem os ditos Juízes ordinários a jurisdição ordinária em todo o seu termo, e distrito, por serem feitos por eleição na forma da lei com a minha sentença e 
terem cartas de Usança e confirmação expedidas em meu nome como Corregedor da Comarca na forma da mesma lei igualmente as que tem nesta Villa os juízes ordinários dela (AHU, GO, Cx. 3, D. 225).

Logo em seguida, o superintendente-geral revela a ordem cronológica das eleições realizadas nos arraiais das minas de Goiás:

E tanto os Juízes Ordinários de Crichás, Meia Ponte e São Felix, e das Terras Novas e seus distritos, como Vmces. nestas Minas de Tocantins, todos foram eleitos muito primeiro, que o fossem os desta Villa [Vila Boa] para a boa administração da justiça dos Povos destas Minas (AHU, GO, Cx. 3, D. 225).

6. Negócios em Lisboa: a venalidade dos ofícios públicos e a cobrança de nOVOS DIREITOS NAS MINAS DE GOIÁS

Mesmo assim, o longo processo de gestação de Vila Boa de Goiás criada somente após a eleição de juízes ordinários e da instalação dos Julgados em alguns arraiais - não impediu a comercialização de cargos oficiais por parte da Coroa, que enxergava, antes mesmo do estabelecimento oficial de Vila Boa, a possibilidade de incrementar os cofres da Real Fazenda através do recebimento de novos direitos provenientes da venda de cargos e ofícios ou das mercês concedidas pelo monarca português. ${ }^{7}$

É o caso, por exemplo, de Miguel Carlos. Alegando ter as qualidades requeridas para o cargo, solicita ao rei de Portugal sua indicação para o ofício de escrivão da câmara e almotaçaria nas minas de Goiás, antecipando-se à própria instalação oficial de Vila Boa. Coincidentemente, seu requerimento foi escrito em fevereiro de 1738, logo após a determinação do governador Gomes Freire de Andrade para que o superintendente-geral realizasse eleições também nos arraiais de Crixás, Sant'Anna e Meia Ponte. Em primeiro de março de 1738, o Conselho Ultramarino encaminha parecer ao monarca com o seguinte teor:

Diz Miguel Carlos que para a Vila novamente criada nas Minas dos Goiás se ha de prover o Oficio de Escrivão da Câmara, e Almotaçaria; E porque o suplicante é pessoa inteligente para servir a dita ocupação como mostra pela atestação dos Escrivães da Relação inserta A V. Majestade seja servida mandar-lhe passar Provisão para servir os ditos ofícios por tempo de hum ano (AHU, GO, Cx. 1, D. 40). 
Interessado no recebimento dos direitos provenientes da venda do oficio de escrivão do Senado da Câmara, ainda que a função fosse inexistente naquele momento, o Conselho Ultramarino lhe confere o direito de atuar no cargo: "A Miguel Carlos se ha de passar Provisão para servir por tempo de um ano os ofícios de Escrivão da Câmara, e Almotaçaria da Vila novamente criada nas Minas dos Goiás, e para pagar os novos direitos que dever se lhe passou este bilhete" (AHU, GO, Cx 1, D. 40). De fato, em 17 de março de 1738, o monarca autoriza, por provisão, sua nomeação para o cargo (AHU, GO, Cx 1, D. 40).

Interessante notar que, como era a primeira vez que este direito estava sendo concedido, o valor correspondente ao cargo de escrivão da câmara não estava ainda definido. Diante disso, em 16 de abril de 1738, foi necessário solicitar ao superintendente-geral das minas de Goiás que fizesse uma avaliação dos ofícios para que se cobrasse os novos direitos (AHU, GO, Cx 1, D. 40).

Acreditamos, então, que havia a consciência de que as instituições associadas ao funcionamento da futura Vila Boa estavam em processo de organização, embora ainda não tivesse sido concebida de fato, senão apenas ordenada sua criação através de provisão do monarca. Neste contexto, atores e protagonistas atuavam num ambiente de antecipação no qual se aguardava a chegada do próximo governador nas minas de Goiás, único autorizado a promover a criação e a instalação dos aparatos de governo municipais.

Em sua solicitação ao rei de Portugal, Miguel Carlos afirma que, para a vila "novamente criada" (termo muito usado e presente nos documentos da época), ou seja, para a vila cuja criação havia sido determinada pelo rei de Portugal, "se ha de prover" (termos que remetem ao futuro) o "Oficio de escrivão da Câmara e almotaçaria”. Percebemos, então, que, durante o tempo que antecedeu a criação de Vila Boa através da eleição dos membros do Senado da Câmara e da demarcação dos lugares dos edifícios públicos, os negócios e acordos envolvendo a ocupação dos cargos oficiais caminhavam de vento em popa, pois, certamente, os protagonistas das transações em apreço tinham em conta uma outra peculiaridade comum ao Império português: além dos interesses particulares, a morosidade dos trâmites administrativos e as longas distâncias geográficas, características que davam forma ao governo e à burocracia portugueses. ${ }^{8}$ Entre a solicitação feita ao monarca, sua apreciação pelo Conselho Ultramarino e a posse de fato no cargo, muito tempo seria necessário.

Curiosamente, após a fundação oficial de Vila Boa, em 11 de outubro de 1739, baseando-se numa certidão anterior, que informava sobre a primeira provisão para o cargo de escrivão da câmara e almotaçaria nas minas de 
Goiás, e atendendo a uma nova petição do mesmo Miguel Carlos, os membros do Conselho Ultramarino renovam por mais um ano a autorização para que exercesse a mesma função, em troca do pagamento dos direitos devidos à Coroa. Na verdade, do nosso ponto de vista, como a última provisão real havia sido despachada em 1738, Miguel Carlos renovava sua nomeação e antecipava a garantia de sua permanência como escrivão da câmara de Vila Boa a partir do segundo semestre de 1740 .

Como o requerimento de Miguel Carlos referia-se especificamente ao ofício de escrivão da câmara na vila que ainda seria criada, parece-nos esclarecedora a leitura de um documento, com data de 28 de setembro de 1739 , redigido pelo superintendente-geral das minas, no qual certifica seu bom desempenho no cargo ocupado na câmara de Vila Boa de Goiás. Ou seja, no período imediatamente após a instituição da primeira vila pelo governador Luiz de Assis Mascarenhas. Diz o documento:

Certifico que Miguel Carlos, escrivão da Câmara e Almotaçaria desta Vila Boa de Goiás por provisão de Vossa Majestade e outro sim Capitão General desta Capitania está servindo nas ditas ocupações com todo o zelo, cuidado e exação, do Real serviço [...]. Pelo que é merecedor de toda a mercê que Vossa Majestade for servido fazer-lhe (AHU, GO, Cx 2, D. 124).

Encontramos o documento acima anexado a uma petição ao rei cujo teor solicitava provisão real para que continuasse desempenhando o mesmo ofício em Vila Boa de Goiás, analisado pelo Conselho Ultramarino em primeiro de fevereiro de 1741. Certamente, logo após ter completado um ano à frente do cargo no Senado da Câmara de Vila Boa, no mês de agosto de 1740, Miguel Carlos já solicitava ao monarca a renovação de seu direito para o próximo ano. Não tardou a resposta do Conselho Ultramarino: "A Miguel Carlos se ha de passar Provisão para servir por tempo de hum ano os Ofícios de Escrivão da Câmara e Almotaçaria de Vila Boa dos Goiás, E para pagar o novo direito que dever se lhe deu este bilhete" (AHU, GO, Cx 2, D. 124).

Desta forma, concluímos que, embora sua primeira solicitação dirigida ao monarca tenha sido atendida em 1738, Miguel Carlos apenas assumiu sua função de escrivão da Câmara após a criação de Vila Boa de Goiás, em junho de 1739, tendo sido reinvestido no cargo durante os anos de 1740 e 1741. Significa dizer que a simples existência de uma petição para a compra de um ofício ou cargo e o despacho de uma provisão real, antes da data de criação e instalação de Vila Boa de Goiás, não nos deve conduzir à conclusão de que a vila já existia enquanto tal ou de que já teria havido eleições para o preenchimento dos cargos municipais.

Fernando Lobo Lemes. Espera, morte e incerteza: a instalaçÃo dos Julgados nas minas de Goiás... 
Caso muito parecido com o de Miguel Carlos, é o de Diogo Jozé Pereira, citado por Pereira Moraes como prova de que já teria havido eleições para a composição de um concelho municipal no arraial de Sant 'Anna, em 1738. Em seu requerimento, a fim de justificar a necessidade do cargo que solicitava ao monarca, Diogo Jozé Pereira alegava que haviam sido providos outros cargos e que a vila já teria sido criada. Mas o texto que integra o documento do Conselho Ultramarino é revelador:

Diz Diogo Joze Pereira que ele tem notícia que por este Tribunal foram providos os Ofícios de escrivão da Câmara, Almotaçaria, Órfãos e Sesmarias para os Goiases, por se achar já criada a Vila, nesta presente frota de 1738 e também se acham providos Escrivão da Correição, Superintendência e Tabelião; e porque necessariamente havendo os ditos Ofícios é preciso o de Inquiridor, distribuidor, e Contador, que se ha de prover por este Tribunal; e na pessoa do suplicante concorrem os requisitos para bem servir o dito Ofício (AHU, GO, Cx 1, D. 51).

Nas entrelinhas do texto podemos ler que Joze Pereira tomou conhecimento ou foi informado que o Conselho Ultramarino estava realizando o provimento de cargos para a Vila de Goiás que, segundo a notícia, já se achava criada. Seu requerimento nos informa que tais ofícios estavam sendo negociados pelo referido Conselho e, neste contexto, insiste na necessidade do provimento dos cargos que lhe interessavam, alegando possuir os requisitos indispensáveis para ocupá-los. Certamente, os ofícios de escrivão da Câmara e almotaçaria, aos quais faz referência, são aqueles objetos da mercê do monarca a Carlos Miguel, como vimos acima.

Por outro lado, vale lembrar que de todos os cargos citados na presente petição, embora sempre exercidos no âmbito municipal, nenhum deles depende de eleições para que sejam preenchidos. São, em essência, posições no universo da venalidade de cargos do Império português, colocados à disposição de particulares, com o intuito de alimentar e expandir as fontes de arrecadação da Coroa. Noutras palavras, não se pode estabelecer nenhuma relação entre o provimento de tais ofícios e a existência de eleições para a escolha de vereadores e juízes ordinários que caracterizam as vilas portuguesas na América.

Quanto à comercialização dos cargos municipais, podemos assistir, ainda uma vez, a antecipação de atos administrativos por parte do Conselho Ultramarino. Na seqüência, em 25 de junho de 1738, em resposta a seu requerimento, Diogo Joze Pereira é agraciado com um "provimento para servir por tempo de hum ano o Ofício de Inquiridor, distribuidor e Contador da 
Vila dos Goiases", em troca do pagamento do novo direito à Coroa (AHU, GO, Cx 1, D. 51). Vale notar que a referência mais próxima encontrada sobre Joze Pereira que confirma sua presença no exercício de um cargo no governo das minas de Goiás, é um certificado, assinado por Luiz de Assis Mascarenhas, no qual o governador o julga merecedor de toda e qualquer graça que o monarca queira lhe oferecer. Este certificado, assinado debaixo do juramento dos Santos Evangelhos, foi registrado em Vila Boa de Goiás, no dia 28 de setembro de 1739 (três meses, portanto, após sua instalação oficial por Assis Mascarenhas) e integra o processo no qual solicita, em 1740, provisão do rei para, por mais um ano, ocupar os mesmos ofícios (AHU, GO, Cx 2, D. 112).

Ainda com relação à realização de eleições nas minas de Goiás, é preciso considerar outro aspecto, levado sempre em conta pelos contemporâneos: os cargos ocupados por eleição, antes da criação de Vila Boa, notadamente os de juízes ordinários, não davam forma a um Senado da Câmara como acontecia com a instituição de uma vila. No mundo dos arraiais, a natureza incompleta das Câmaras Municipais, era sempre motivo para requerer do monarca o estatuto de vila, com todas as vantagens que tal título implicava. É o que pretendiam, por exemplo, os representantes do julgado de Meia Ponte, quarenta anos depois da primeira eleição realizada sob o controle de Agostinho Pacheco Teles. Tentando sensibilizar o monarca, em janeiro de 1779, afirmam que

Há quarenta anos completos, que aquele território de Minas denominado Meia Ponte passou à Julgado com ereção de Concelho do qual são os suplicantes os presidentes, que se confirmou por Carta do Conselho Ultramarino de trinta e um de outubro de 1739, Sem que ate o presente passasse de Julgado a Villa capacitada com Câmara inteira gozando aquelas prerrogativas, liberdades, e isenções, que costumam ser inseparáveis de qualquer Vila famosa de todo o continente de Minas, fazendo se semelhante concelho merecedor de tal regalia por muitas justificadas razões (AHU, GO, Cx 31, D. 1961).

Queremos destacar através da leitura desta carta a verdadeira pretensão de seus autores junto ao rei de Portugal: nos arraiais com estatuto de julgado, os concelhos existentes são percebidos a partir da noção de câmara incompleta ou meia-câmara, sem as vantagens de uma "câmara inteira" como ocorre com a fundação de uma vila. Quarenta anos mais tarde, os presidentes do concelho do arraial de Meia Ponte ainda governavam a região na condição de Julgado, a partir de uma estrutura administrativa

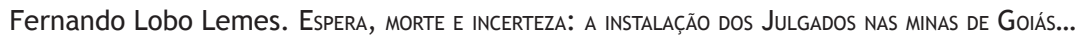


local baseada numa câmara incompleta. Desde logo, durante todo o século XVIII, apenas uma vila e uma "câmara completa" foram constituídas em todo o território das minas de Goiás: nem antes, nem depois da composição do Senado da Câmara e da criação de Vila Boa de Goiás por iniciativa do governador da Capitania de São Paulo, Luiz de Assis Mascarenhas, durante o mês de julho de 1739 .

\section{CONCLUSÃO}

Do nosso ponto de vista, portanto, a primeira vila das minas de Goiás, não foi criada em 1736, através de provisão real, nem, tampouco, apenas erigida ou instalada parcialmente em 1739, por meio dos atos do governador da Capitania de São Paulo, que demarcou logradouros e mandou erguer os prédios públicos.

Entre a ordem do rei de Portugal para a criação da primeira vila, em fevereiro de 1736, e sua instalação efetiva, com a eleição do Senado da Câmara, em julho de 1739, um tempo de espera se instalou nas minas de Goiás. Distante, entretanto, de um quadro marcado pela imobilidade. Ao contrário, neste cenário obscuro e imprevisível foi, antes, a precipitação e a antecipação de escolhas e decisões que definiram as tintas e as cores do conjunto político e administrativo elaborado nas minas de Goiás.

Neste tempo intermediário, é preciso pensar entre e através dos marcos visíveis que cercam os acontecimentos, evitando uma leitura que lhes empresta uma imagem estática, dissociando-os de sua natureza provisória e plena de incertezas. É exatamente por isso que precisamos levar em consideração as especificidades das situações intermediárias, os "intermeios", a fim de desvendar estes tempos flutuantes, de movimentos incessantes, às vezes surpreendentes. São tempos selados pela incerteza, são passagens no tempo e no espaço que circunscrevem os acontecimentos a esferas e momentos marcados por mutações inesperadas (VIDAL, 2005b, p. 81).

Alem disso, é sob o prisma da interação entre atores e protagonistas, sem a intenção primeira de revelar suas estruturas, que devemos caminhar por entre os escombros de um momento obscuro construído pelos homens do passado. Interações através das quais se projetam com toda a força e intensidade os arranjos e as recomposições que emergem à superfície da história, permitindo entrever as tramas, os acordos, as novas direções, a definição de outros destinos. Como se as pecas postas sobre o tabuleiro pudessem, a qualquer momento, ser reorganizadas em função de um resultado diferente e inesperado. 
Finalmente, entre a ordem do rei de Portugal para a criação da primeira vila, em fevereiro de 1736, o desaparecimento do Conde de Sarzedas, em agosto de 1737, e a chegada do governador Luiz de Assis Mascarenhas, em junho de 1739, como pano de fundo deste cenário marcado pela presença de representantes oficiais da Coroa no território das minas de Goiás, podemos observar situações intermediárias, compostas de decisões e atitudes de natureza provisória: a criação de Julgados enquanto solução paliativa ao adiamento do ato de criação da primeira vila, a eleição de autoridades locais antes da instalação oficial do Senado da Câmara ou a compra e venda de cargos e ofícios pouco antes da instalação de Vila Boa de Goiás. Por trás dos acontecimentos datados, de maior visibilidade, tantas vezes confirmados pelas penas dos cronistas que narram a história de Goiás, vemos emergir eventos de natureza intermediária que revelam reações e adaptações entre os protagonistas, cujos interesses produzem arranjos, composições e recomposições que interferem e formatam o cenário político e institucional das minas de Goiás.

\section{WAIT, DEATH AND UNCERTAINTY: THE INSTALLATION OF THE JULGADOS IN THE MINES OF GoIÁs - READINGS ABOUT THE CREATION OF VILA BOA}

АвsтRACт: From of the administrative mechanisms that defined the contours of the colonial Government, the institution of the Julgados, an initial step toward a stronger institutional base, appears as provisional strategy of organization of the coordinates actions by Lisbon in Goiás. In this context, from of the observation of the political changes created by waiting situations, we propose a read possible about the creation of Vila Boa, analyzing the emergence of events of intermediate nature, characterized by uncertainty, how the example of the death of the Governor of the captaincy of São Paulo, that reveal reactions and adjustments between the protagonists, whose interests create compositions and format the political and institutional scenery of mines of Goiás.

KeYwORDs: Goiás; Julgados; Wait; Colonial Government.

\section{Notas EXPLICATIVAS}

1 Na trama das relações políticas e econômicas do Império, os interesses pessoais dos oficiais da Coroa são facilmente perceptíveis nas transações que realizavam, mesclando vantagens particulares às altas atividades ligadas à diplomacia imperial. Em Goiás não era diferente. Apenas a título de ilustração, ALENCASTRO cita dois casos interessantes envolvendo negócios de autoridades portuguesas: No primeiro caso, relativo ao asiento português, conta-nos que

Fernando Lobo Lemes. Espera, mORTE E INCERTEZA: a InSTALAÇÃo dos JulGados nas minas de Golás... 
"João Rodrigues Coutinho era sócio de seu irmão, Gonçalo Vaz Coutinho, o qual obteve, por sua vez, o asiento até o ano de 1609. Um dos filhos deste último, Francisco de Sousa Coutinho, chefe da diplomacia portuguesa após a Restauração (1640), atuou com determinação junto às Províncias-Unidas e nas cortes européias, a fim de restabelecer a soberania de Lisboa sobre Angola e o Brasil. Com isso, os descendentes dos irmãos Coutinho permaneceram ativos no Atlântico-Sul". Noutro caso, diz ele, "Os três governadores brasílicos de Angola Salvador de Sá (1648-1652), João Fernandes Vieira (1658-1661) e André Vidal de Negreiros (1661-1666) - bem como os oficiais que os acompanhavam, possuíam propriedades escravagistas no Rio de Janeiro, em Pernambuco ou na Paraíba, de onde acompanhavam a evolução de Angola" (ALENCASTRO, 2006, p. 341-344).

2 No período inicial da exploração de ouro nas minas de Goiás, vigorava o método de "quintamento" nas casas de fundição. Desde que o Alvará de 1618 regulamentou a cobrança do quinto, este era o décimo primeiro método empregado pela Coroa portuguesa no Brasil (PALACIN, 2001, p. 48). No Brasil colonial o recolhimento do quinto foi implantado em 1734, na futura Demarcação Diamantina, cuja capital era o Tijuco, atual Diamantina. Por sua vez, a partir de 1735, o sistema de capitação foi adotado nas Capitanias de Minas Gerais e de São Paulo, particularmente nas regiões de mineração de Goiás e Mato Grosso. Durante o recolhimento da capitação, o imposto do quinto era suspenso e se autorizava a abertura das rotas e caminhos e a livre circulação de ouro em pó. Efetivamente, a capitação foi um processo de recolhimento de direitos reais que sofreu violentas contestações. Pouco antes de sua implantação várias tentativas de reivindicações visando o retorno ao método anterior ocorreram até o ano de 1750, quando o rei José I decide por sua suspensão (MAGALHÃES, 2009, p. 118-132).

3 Conceitos essenciais para as idéias apresentadas no presente artigo, desenvolvemos, mais largamente, em outro estudo, as noções de ritmo e temporalidade associados às situações de espera na história de Goiás do século XVIII (LEMES, 2011). Contudo, neste aspecto, lembramos aqui a advertência de Laurent Vidal quanto às possibilidades metodológicas para a compreensão da complexa sociedade colonial portuguesa. "Entre os caminhos percorridos para entender a complexidade das sociedades urbanas", diz ele, "aquele relacionado aos arranjos sociais criados pelas situações de espera foi negligenciado. Percorrêlo, significa perceber que neste imenso império transoceânico dos Portugueses, as distâncias de tempo criam situações de espera - espera administrativa ou familiar - e que estas situações abrem verdadeiras brechas para novas experiências políticas e sociais" (VIDAL, 2011). Nesta direção, é este olhar lançado sobre as situações intermediárias, em um momento específico da história de Goiás, que vai nortear as idéias expostas no presente estudo. Sobre o tema, ver também o trabalho inovador de VIDAL (2012) publicado no dossiê especial da revista Questions Internationales dedicado ao Brasil e texto coletivo de VIDAL, MUSSET E VIDAL (2011). 
4 A instituição de Julgados constitui a principal medida tomada por Lisboa e governadores em terras de conquista que visa a implantação de estruturas administrativas e jurídicas em lugares nos quais achavam prematuro ou inadequado a criação de vilas. De acordo com Fonseca, os Julgados eram constituídos por territórios sob a jurisdição de um único juiz ordinário (juiz não diplomado de primeira instância, cujas atribuições podem ser diferentes daqueles que atuam numa vila, através do senado da câmara), com autonomia judiciária parcial ou incompleta, o que equivale a dizer, sem jurisdição completa, seja no aspecto civil ou criminal, e sem autonomia administrativa, o que o torna dependente de um concelho ou vila mais próxima (2003, p. 202203). Em Goiás, os Julgados foram instituídos antes da criação de Vila Boa de Goiás, através da eleição de juízes ordinários que, por sua vez, detinham poder judicial e administrativo, acumulando e ampliando, paulatinamente, sua autonomia e seus poderes, sem, contudo, jamais adquirir o estatuto de concelho ou o título de vila, embora alguns deles tenham buscado insistentemente adquirir esta condição.

5 Com a descoberta do ouro e a ocupação do território das minas de Goiás, as leis que aqui passaram a vigorar eram as mesmas do reino. Assim, tivemos as Ordenações do Reino e as de caráter geral. Com o passar do tempo as especiais, ou seja, as que eram feitas especialmente para o Brasil, sendo que destas as principais eram os Regimentos. Ao lado do direito que vinha do Reino, tivemos o direito local, que emanava dos órgãos da administração colonial e, mais tarde, das Câmaras Municipais, que atendiam às necessidades peculiares da Colônia (VAINFAS, 2001). Quanto às Ordenações, foram três os códigos sucessivos que receberam o nome de Ordenações do Reino: as Afonsinas (1446-47), as Manuelinas (1521) e as Filipinas (1603), constituindo-se em elementos de fundamental importância na prática política e administrativa em toda a vasta extensão dos domínios portugueses. O conhecimento de seu conteúdo por parte dos oficiais da Coroa era pressuposto essencial para o governo do império (BANDECCHI, 1972).

6 A preferência de Sarzedas, seguida por seu sucessor, Luiz de Assis Mascarenhas, era pelo arraial de Sant 'Anna. De fato, o superintendente-geral, Agostinho Pacheco Teles, ao sugerir ao monarca sua preferência quanto ao sítio ideal para a instalação da primeira vila, revela que a opção feita, em 1737, pelo então governador de São Paulo, o Condede Sarzedas não era o arraial de Meia Ponte. Em suas palavras, "o lugar mais próprio para ela [a vila], contra a inclinação do dito governador Condede Sarzedas [...], me pareceu sempre, e parece o da Meia Ponte, assim por ter o clima mais saudável, e de melhor águas, como posição, em paragem mais acomodada, para todos os povos destas Minas" (AHU, GO, Cx. 1, D. 60).

7 A nomeação e venda de cargos e ofícios era conseqüência das formas de administração implantadas pela Coroa no Brasil, revelando a prática de

Fernando Lobo Lemes. Espera, mORTE E INCERTEZA: a InSTALAÇÃo dos JulGados nas minas de Golás... 
um mecanismo bastante peculiar, que associava interesses sociais e poderes administrativos: a nomeação de pessoas para determinados cargos, acompanhava uma lógica ligada à venalidade dos ofícios pela monarquia portuguesa. Embora tanto a venda privada, quanto a venda de ofícios pela Coroa fossem proibidas anteriormente, um decreto real de 18 de maio de 1722, estabeleceu que os novos ofícios fossem dados àquelas pessoas que tivessem oferecido um donativo à Fazenda Real. De fato, tal prática consistia numa forma de serviço prestado em contrapartida a uma mercê ou graça do monarca, relativa ao oficio, no interior de uma rede de benefícios. Mais tarde, a partir de 1740, o regime do donativo foi estendido a todos os ofícios (HESPANHA, 2001, p. 183).

8 De um ponto de vista mais vasto, o tema da distância é muito comum nas análises dos problemas associados ao sistema colonial e à administração do Império português. Não raro é invocado na historiografia brasileira como fator de grande relevância para a compreensão das relações de poder no período colonial. Ver, por exemplo, obras e artigos importantes que tratam do tema, tais como: SOUZA (2006), FRAGOSO; GOUVÊA (2010), SOUZA; FURTADO; BICALHO (2009), BICALHO; FERLINI (2005), RAMINELLI (2008); ARAÚJO (2000) e DEAN (1990).

\section{REFERÊNCIAS BIBLIOGRÁFICAS}

Alencastro, Luiz Felipe de. Le versant brésilien de l'Atlantique sud: 1550-1850. Annales HSS, 2006, n. 2, p. 339-382.

ARAújo, Emanuel. Tão vasto, tão ermo, tão longe: o sertão e o sertanejo nos sertões coloniais. In: PRIORE, Mary Lucy del (Org.). Revisão do Paraíso: os brasileiros e o Estado em 500 anos de história. Rio de janeiro: Campus, 2000.

Bandecchi, B. O. O Município no Brasil e sua Função Política. Revista de História. São Paulo, n. 90, p. 495-530, 1972.

Bicalho, Maria Fernanda; Ferlini, Vera Lúcia Amaral (Orgs.). Modos de Governar: Idéias e práticas políticas no Império português, séculos XVI a XIX. São Paulo: Alameda, 2005.

DeAn, Warren. The frontier in Brazil. In: Frontiers in comparative perspectives. Washington D. C: The Woodrow Wilson Center, 1990.

Fonseca, Cláudia Damasceno. Des terres aux villes de lor. Pouvoir et territoires urbains au Minas Gerais (Brésil, XVIIIe siècle). Paris: Centre Culturel Calouste Gulbenkian, 2003.

Fragoso, João Ribeiro; GouvêA, Maria de Fátima Silva (Orgs.). Na Trama das Redes. Política e negócios no império português. Séculos XVI-XVIII. Rio de Janeiro: Civilização Brasileira, 2010. 
Hespanha, Antônio Manuel. A constituição do Império português. Revisão de alguns enviesamentos correntes. In: Fragoso, João Fragoso; BiCalho, Maria Fernanda Batista; GouvÊA, Maria de Fátima (Dir.). O Antigo Regime nos Trópicos: a dinâmica imperial portuguesa (séculos XVI-XVIII). Rio de Janeiro: Civilização Brasileira, 2001, p. 163-188.

Hespanha, Antônio Manuel. Vísperas del Leviatán - Instituciones y poder político (Portugal, siglo XVII). Madri: Taurus Humanidades, 1989.

Lemes, Fernando Lobo. Pouvoir politique et réseau urbain dans l'Amérique coloniale: mines e capitainerie du Goiás au XVIIIe et XIXe siècles. Tese em História, IHEAL, Universidade Sorbonne Nouvelle - Paris 3, 497 p., 2011.

Magalhães, Joaquim Romero. A cobrança do ouro do rei nas Minas Gerais: o fim da capitação - 1741-1750. Tempo, 2009, n. 27, p. 118-132.

Moraes, Cristina de Cássia Pereira. O corpo místico de Cristo - Irmandades e Confrarias na Capitania de Goiás (1736-1808). Tese em História, Universidade de Lisboa: 2005.

Palacin, Luis. O século do ouro em Goiás 1722-1822: Estrutura e conjuntura numa Capitania de minas. Goiânia : UCG, 2001.

RAMINELli, Ronald José. Viagens Ultramarinas: monarcas, vassalos e governo à distância. São Paulo: Alameda, 2008.

Souza, Laura de Mello e. La conjoncture critique dans le monde luso-brésilien au début du XVIIIe siècle. Le Portugal et l'Atlantique. Paris: Centro Cultural Calouste Gulbenkian, 2001, v. 42, p. 11-24.

Souza, Laura de Mello e. O sol e sombra - Política e administração na América portuguesa do século XVIII, São Paulo: Companhia das Letras, 2006.

Souza, Laura de Mello; Furtado, Júnia Ferreira; Bicalho, Maria Fernanda (Orgs.). O governo dos povos: Relações de poder no mundo ibérico da Época Moderna. São Paulo: Alameda, 2009.

Vainfas, Ronaldo (Org.). Dicionário do Brasil Colonial (1500-1808). Rio de Janeiro: Objetiva, 2001.

VIDAL, Laurent. Le pays de l'attente, Questions internationales, n. 5, 2012, p. 45-52.

VIDAL, Laurent. Cidades em espera, sociedades em espera no Brasil-colônia: alguns desafios metodológicos. Texto inédito, 2011.

VIDAL, Laurent. Mazagão: la ville que traversa l'Atlantique - Du Maroc à l'Amazonie (1769-1783). Paris: Flammarion, 2005(a).

VIDAL, Laurent. Os trilhos da história do Brasil urbano. Ler História, 2005(b), n. 48, p. 75-85.

Vidal, Laurent; Musset, Alain; Vidal Dominique. "Sociedades, mobilidades, deslocamentos: os territórios da espera. O caso dos mundos americanos (de ontem a hoje)", Confins [Online], n. 13, 2011. Acesso em 11 junho 2012. Disponível em http://confins.revues.org/7274;DOI:10.4000/confins.7274

Fernando Lobo Lemes. Espera, mORTE E INCERTEZA: a InSTALAÇÃo dos JulGados nas minas de Golás... 


\section{FONTES PRIMÁRIAS MANUSCRITAS}

AHU/GO/Consulta do Conselho Ultramarino, ao rei D. João V, sobre a carta do intendente e provedor das Minas de Goiás, Sebastião Mendes de Carvalho, dando conta de haver tomado posse daquela Intendência, do que obrara a respeito da cobrança da capitação e solicitando a remessa, com brevidade, de livros e bilhetes. Lisboa, 31 de maio de 1738 [Cx. 1, D. 50].

AHU/GO/Consulta do Conselho Ultramarino, ao rei D. João V, sobre a carta do superintendente-geral das Minas de Goiás, [Agostinho Pacheco Teles], acerca da criação dos cargos de juízes e demais ofícios e o estabelecimento da vila que se tem mandado erigir. Lisboa, 7 de julho de 1739 [Cx. 1, D. 60].

AHU/GO/Consulta (cópia) do Conselho Ultramarino, ao rei D. João V, sobre carta do intendente e provedor da Fazenda Real de Goiás, Sebastião Mendes de Carvalho dando conta da resolução tomada pelo [governador e capitão-general de São Paulo], Condede Sarzedas, [D. António Luís de Távora], acerca do valor da capitação dos escravos naquelas Minas. Lisboa, 6 de setembro de 1738 [Cx. 1, D. 53].

AHU/GO/Consulta do Conselho Ultramarino, ao rei [D. João V], sobre a súplica feita pelos mineiros do descoberto do Tocantins, solicitando a entrada de gado dos currais da Bahia, naquelas minas. Lisboa, 27 de janeiro de 1736 [Cx. 1, D. 24]. AHU/GO/Carta Régia (cópia) do rei D. João V, ao governador e capitão-general de São Paulo, Condede Sarzedas, [D. António Luís de Távora], ordenando que o bacharel Agostinho Pacheco Teles seja o sucessor do superintendente-geral das Minas de Goiás, Gregório Dias da Silva. Lisboa, 11 de fevereiro de 1736 [Cx. 1, D. 25].

AHU/GO/Consulta do Conselho Ultramarino, ao rei D. José, sobre o requerimento do ex-governador e capitão-general de São Paulo, D. Luís de Mascarenhas, solicitando remuneração pela criação de Vila Boa de Goiás. Lisboa, 15 de novembro de 1752 [Cx. 7, D. 549].

AHU/GO/Carta (cópia) do [governador e capitão-general de São Paulo], D. Luís de Mascarenhas, ao rei [D. João V], sobre os atos dos juízes dos arraiais de Crixás e Meia Ponte, os quais sugeridos pelo [ex-ouvidor de Goiás], bacharel Agostinho Pacheco Teles não sujeitaram seus arraiais à jurisdição de Vila Boa. Santos, 27 de julho de 1743 [Cx. 3, D. 225].

AHU/GO/Requerimento de Miguel Carlos, ao rei [D. João V], solicitando provimento para servir por tempo de um ano no ofício de escrivão da Câmara e Almotaçaria da Vila de Goiás. Lisboa, 1 de março de 1738 [Cx. 1, D. 40].

AHU/GO/Requerimento do escrivão da Câmara e Almotaçaria de Vila Boa das Minas de Goiás, Carlos Miguel, ao rei [D. João V], solicitando provisão para continuar servindo no mesmo ofício por mais um ano. Goiás, [ant.] 1 de fevereiro de 1741[Cx. 2, D. 124]. 
AHU/GO/Requerimento de Diogo José Pereira, ao rei [D. João V], solicitando ser provido no ofício de inquiridor, contador e distribuidor das Minas de Goiás. Lisboa, [ant.] 14 de junho de 1738 [Cx. 1, D. 51].

AHU/GO/Requerimento do distribuidor, inquiridor e contador das Minas de Goiás, Diogo José Pereira, ao rei [D. João V], solicitando provisão para por mais um ano servir os mesmos ofícios. Goiás, [ant.] 29 de outubro de 1740 [Cx. 2, D. 112].

AHU/GO/Carta dos juízes ordinários do julgado da Meia Ponte, à rainha [D. Maria I], solicitando que se crie Vila, Câmara inteira e Conselho no arraial de Meia Ponte, com as respectivas obras públicas que necessita aquela comarca para se transformar em vila, ficando-lhe anexados alguns arraiais e Julgados vizinhos. Goiás, [ant.] 29 de janeiro de 1779 [Cx. 31, D. 1961]. 